\title{
Life-threatening hyperkalemia in a patient with normal renal function
}

\author{
Taha Ayach ${ }^{1}$, Robert W. Nappo ${ }^{2}$, Jennifer L. Paugh-Miller ${ }^{1}$ and Edward A. Ross ${ }^{1}$ \\ ${ }^{1}$ Division of Nephrology, Hypertension and Renal Transplantation, University of Florida, Gainesville, FL, USA and ${ }^{2}$ Shands Hospital, \\ University of Florida, Gainesville, FL, USA \\ Correspondence and offprint requests to: Edward A. Ross; E-mail: rossea@medicine.ufl.edu
}

\begin{abstract}
With media focus on benefits from reducing sodium intake, there is increased popularity of salt substitutes, typically potassium chloride. While viewed by the public as a healthy alternative to standard table salt, less appreciated is the severe risk with certain comorbidities and medications. We report the case of an elderly female with chronically high salt substitute intake, normal renal function, diabetes, hypertension treated with angiotensin-converting enzyme inhibitor and beta blockade, who developed life-threatening hyperkalemia after a minimally invasive outpatient procedure. We describe the pathophysiology of the disruption in potassium homeostasis and emphasize the importance of dietary history and educating high-risk patients to avoid salt substitutes.
\end{abstract}

Keywords: ACE inhibition; arrhythmia; hyperkalemia; salt; salt substitute

\section{Introduction}

With the highly publicized benefits of consuming a lowsalt diet, salt substitutes are marketed as having a similar taste but circumventing the risk of hypertension and cardiovascular disease associated with a high intake of sodium chloride. They typically are composed of potassium chloride and may be viewed by the public as a healthy alternative to standard table salt [1]. Although there are several benefits from high potassium intake [2], certain medical conditions, principally renal disease and diabetes mellitus, predispose to the development of hyperkalemia. Underappreciated, however, is that a constellation of factors can lead to critical rises in plasma potassium levels in the absence of chronic kidney disease. Thus, we report here a case of life-threatening hyperkalemia secondary to the use of salt substitute in a patient with normal renal function, and review the pathophysiology of the associated medical factors that disrupted normal potassium homeostasis.

\section{Case presentation}

A 72-year-old female with a past medical history of hypertension, type 2 diabetes mellitus, paroxysmal atrial fibrillation and osteoporosis developed a new painful vertebral compression fracture. Her medications included quinapril, metoprolol, insulin, oral hypoglycemic agents, amiodarone and warfarin. She underwent an uneventful elective outpatient minimally invasive kyphoplasty procedure and returned home. Within a few hours she began complaining of weakness in all extremities and generalized fatigue. Upon ambulance arrival she was diaphoretic with bradycardia at $\sim 40 \mathrm{bpm}$, had a transient response to intravenous atropine and was transferred to our emergency room (University of Florida, Shands Hospital, Gainesville, FL, USA). Her initial vital signs demonstrated a heart rate of $32 \mathrm{bpm}$ and blood pressure of $110 / 60 \mathrm{mmHg}$. The previously unremarkable electrocardiogram newly showed the absence of $P$ waves, a junctional rhythm, peaked $T$ waves and a wide-complex QRS with right bundle branch block morphology (Figure 1). Plasma laboratory studies revealed sodium $134 \mathrm{mmol} / \mathrm{L}$, potassium $9.8 \mathrm{mmol} / \mathrm{L}$, chloride $108 \mathrm{mmol} / \mathrm{L}, \mathrm{CO}_{2}$ content $20 \mathrm{mmol} /$ $\mathrm{L}$, blood urea nitrogen $25 \mathrm{mg} / \mathrm{dL}(8.9 \mathrm{mmol} / \mathrm{L})$, creatinine $1.2 \mathrm{mg} / \mathrm{dL}$ (106.1 $\mu \mathrm{mol} / \mathrm{L}$, baseline $0.8-0.9 \mathrm{mg} / \mathrm{dL}$, 70.7$79.6 \mu \mathrm{mol} / \mathrm{L})$, glucose $363 \mathrm{mg} / \mathrm{dL}$ (20.1 mmol/L) and her other results were unremarkable. Urine testing showed sodium $68 \mathrm{mmol} / \mathrm{L}$, potassium $180.9 \mathrm{mmol} / \mathrm{L}$, chloride $238 \mathrm{mmol} / \mathrm{L}$ and $\mathrm{pH}$ 5.5. She began vomiting and became lethargic and so she was given $2 \mathrm{~L}$ of normal saline intravenously, intubated for airway protection, and was transcutaneously paced at a rate of $60 \mathrm{bpm}$. Arterial blood sampling done after intubation had a pH 7.29, $\mathrm{pCO}_{2}$ of 43 $\mathrm{mmHg}$ and an oxygen saturation of $100 \%$. The hyperkalemia was initially treated with intravenous insulin, furosemide, bicarbonate and calcium gluconate, which resulted in narrowing of her QRS complex with return of $\mathrm{P}$ waves (Figure 2). In that her plasma potassium concentration 


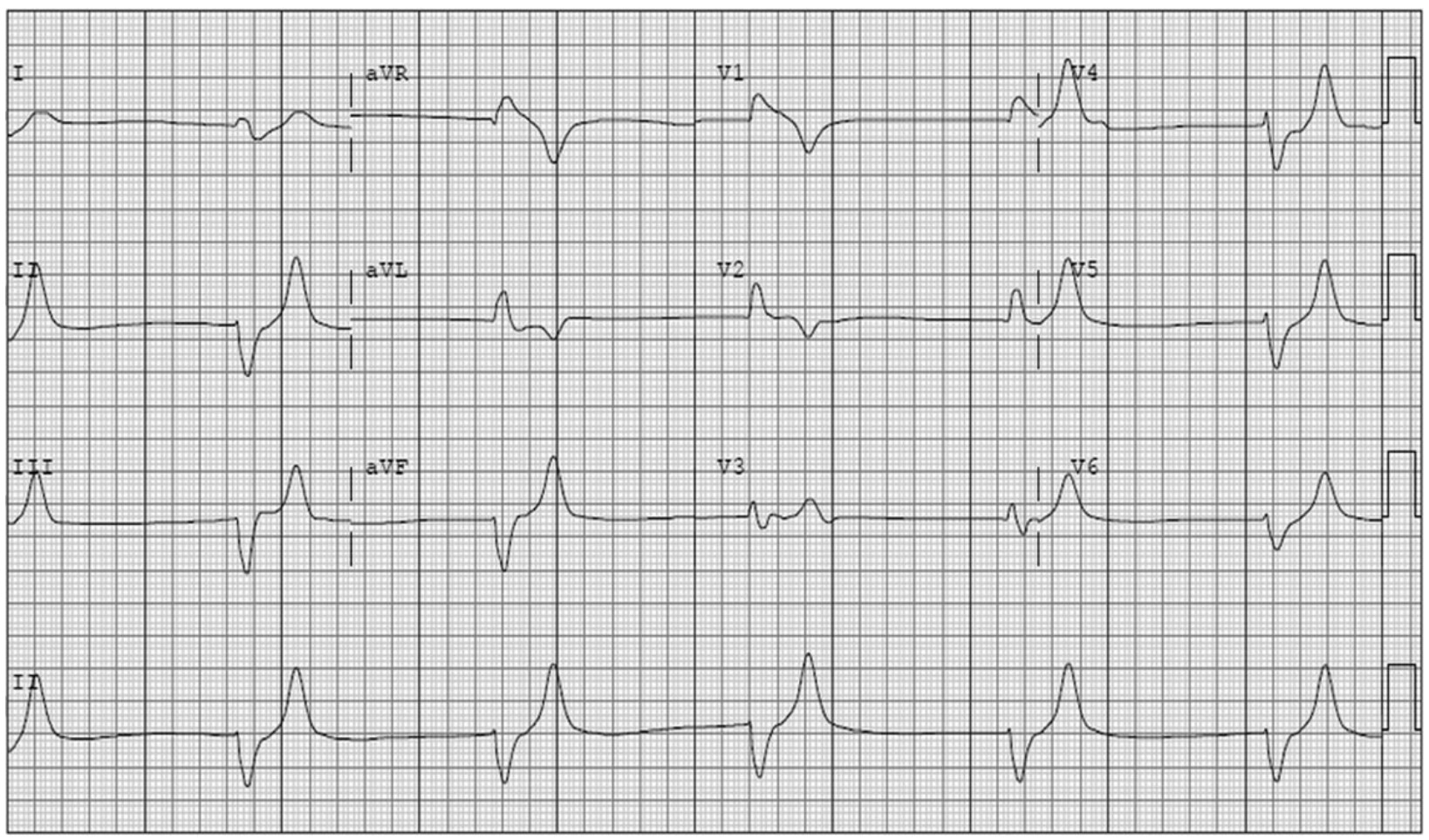

Fig. 1. Electrocardiogram demonstrating severe hyperkalemia on admission before treatment.

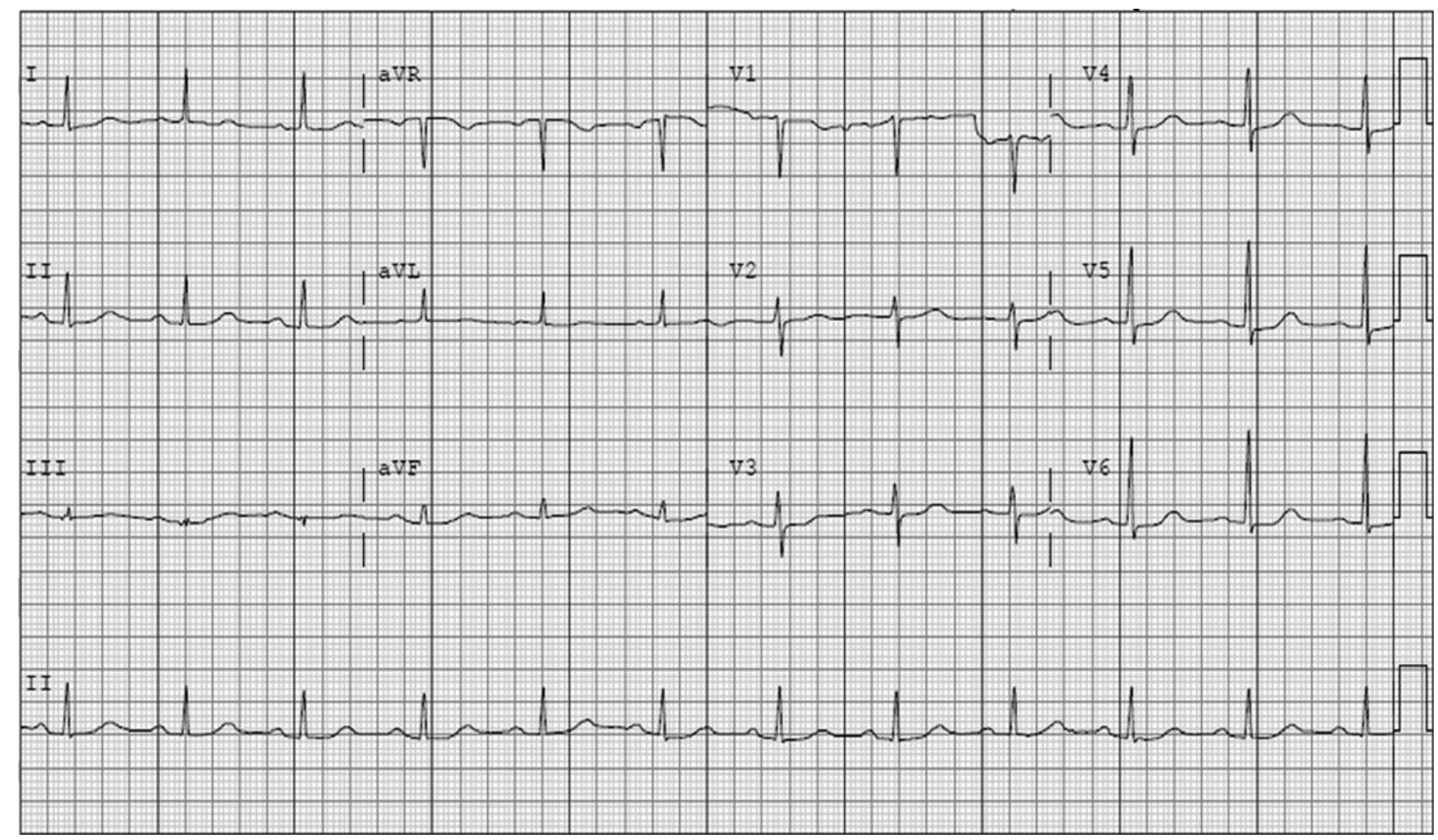

Fig. 2. Electrocardiogram after correction of the hyperkalemia.

only declined to $7.9 \mathrm{mmol} / \mathrm{L}$, with medical treatment, she underwent emergency hemodialysis. Her follow-up potassium levels were, and remained, within normal limits. Further history was obtained upon the arrival of the patient's husband which helped elucidate the cause of the critical hyperkalemia. This case presentation follows the guidelines of the Institutional Review Board (University of Florida). 


\section{Discussion}

Surgical procedures are frequently associated with a multitude of factors that can lead to postoperative hyperkalemia with its attendant increased risk of morbidity and mortality. The causes are diverse and can be broadly classified into those with altered potassium distribution (e.g. increased potassium release from cells or other transcellular shifts), reduced urinary excretion (e.g. reduced sodium delivery, volume depletion, and hypoaldosteronism) or an exogenous potassium load (e.g. blood transfusions). Certain acute conditions and chronic comorbidities present particular risk. These include chronic kidney disease, diabetes mellitus, many outpatient preoperative medications (e.g. beta blockers, salt substitutes) and perioperative agents (e.g. succinylcholine, hyperosmolar volume expanders).

In our patient there was no immediately obvious single cause of the life-threatening hyperkalemia. The initial concern was that she had received a peri-procedure medication that induced a transmembrane potassium shift into plasma. A careful review of the operative record failed to show any such administration, and she had only been given IV midazolam, fentanyl and cefazolin. There was no potassium given at any time during procedure. On further questioning, her husband reported that she was using large quantities of a salt substitute (NoSalt $\left.{ }^{\circledR}\right)$, which contains $650 \mathrm{mg}(16.6 \mathrm{mEq})$ of potassium in each serving (0.25 teaspoon, $1.25 \mathrm{~mL}$ ). After extubation she confirmed that she took this supplement on a daily basis for the last 6 months. The patient's estimated daily intake was $\sim 3-4$ teaspoons (200-266 mEq potassium), which was in addition to and greatly exceeding that from her dietary intake. The typical daily Western diet contains 70-150 $\mathrm{mEq}$ potassium. Notably, she did not have a history of CKD, and she denied taking any NSAIDs for her back pain. Creatinine on presentation, however, was slightly increased above her baseline and we believe this prerenal dysfunction was secondary to volume depletion from her preoperative fasting status. This was consistent with the fractional excretion of sodium being $0.5 \%$. After volume resuscitation her transtubular potassium gradient was appropriately $>10 \%$. She was discharged with normal potassium and creatinine levels, and was told to abstain from using salt substitutes.

This patient's critical hyperkalemia was likely multifactorial but mainly related to an unintended high potassium intake from the salt substitute that overwhelmed the potassium excretion ability of the kidneys in the setting of multiple risk factors for developing hyperkalemia including the following:

- Reduced aldosterone production secondary to the hyporeninemic hypoaldosteronism commonly seen in diabetic patients [3] and the use of angiotensin-converting enzyme (ACE) inhibitors.

- Decreased distal tubular flow and sodium delivery secondary to volume depletion [4]

- Decreased renal function due to renin-angiotensinaldosterone-system blockade with volume depletion;

- Adrenergic beta blockade predisposing to hyperkalemia by suppressing catecholamine-stimulated renin release, thereby decreasing aldosterone synthesis [5] and also by inhibiting Na-K ATPase (decreasing flux of potassium into cells [6]).

- Metabolic acidosis leads to potassium movement into the extracellular fluid, which causes decreased potassium
Table 1. Major causes of hyperkalemia in the perioperative patient ${ }^{a}$

\begin{tabular}{|c|c|}
\hline Mechanism & Causes \\
\hline $\begin{array}{l}\text { Reduced urinary } \\
\text { potassium excretion }\end{array}$ & $\begin{array}{l}\text { Reduced aldosterone production } \\
\text { Renal disease } \\
\text { NSAIDs } \\
\text { Calcineurin Inhibitors } \\
\text { ACE-I, ARBs and direct renin inhibitors } \\
\text { Heparin } \\
\text { Reduced response to aldosterone } \\
\text { Potassium-sparing diuretics } \\
\text { Spironolactone, eplerenone, amiloride, } \\
\text { triamterene } \\
\text { Antibiotics } \\
\text { Trimethoprim, and pentamidine } \\
\text { Pre-renal state with reduced distal sodium } \\
\text { delivery and tubular flow } \\
\text { AKI } \\
\text { CKD }\end{array}$ \\
\hline $\begin{array}{l}\text { Altered potassium } \\
\text { distribution }\end{array}$ & $\begin{array}{l}\text { Increased potassium release from cells } \\
\text { Hyperosmolality: hyperglycemia, mannitol } \\
\text { Rhabdomyolysis } \\
\text { Trauma } \\
\text { Operative malpositioning of patient } \\
\text { Ischemia } \\
\text { Propofol } \\
\text { Succinylcholine } \\
\text { Hemolysis } \\
\text { Transcellular shift and impaired cellular } \\
\text { uptake } \\
\text { Beta blockers } \\
\text { Acidosis } \\
\text { Digitalis } \\
\text { Malignant hyperthermia }\end{array}$ \\
\hline $\begin{array}{l}\text { Exogenous potassium } \\
\text { load }\end{array}$ & $\begin{array}{l}\text { Potassium supplements } \\
\text { Salt substitutes } \\
\text { Medications: penicillin G and citrate } \\
\text { Blood transfusions }\end{array}$ \\
\hline
\end{tabular}

${ }^{\text {a } M o d i f i e d ~ f r o m ~ A y a c h ~ e t ~ a l . ~ P o s t o p e r a t i v e ~ h y p e r k a l e m i a ~(s u b m i t t e d) . ~}$

secretion, increased reabsorption in the collecting duct and hence causes hyperkalemia [7].

In the perioperative patient it is important to consider additional potential causes of hyperkalemia (Table 1), which were not present in this patient: (i) other exogenous agents presenting a potassium load (e.g. blood transfusions [8], intravenous potassium-containing fluids, certain penicillin $\mathrm{G}$ and citrate formulations); (ii) altered potassium distribution due to release from cells (e.g. hyperosmolar volume expanders, succinylcholine [9], rhabdomyolysis from trauma, propofol [10], tissue dissection, ischemia or pressure as in malpositioning during bariatric surgery [11]) or from transcellular shifts with impaired cellular uptake (e.g. beta blockers, acidosis, digitalis) and (iii) factors reducing urinary potassium excretion (e.g. heparin, potassium-sparing diuretics, antibiotics such as trimethoprim and pentamidine).

In recent years the medical and lay media focus on the benefits of a low-salt diet has led to the increased popularity of salt substitutes as a healthy alternative [1]. There are also several recognized benefits from a high potassium intake, which include lowering blood pressure and reducing the risk of stroke and ventricular arrhythmias in patients with heart disease [2]. Unfortunately, there has not been similar public attention to the potential risks in susceptible populations, despite reports of the risks for severe hyperkalemia [12-14]. Although containers of the salt substitute described here clearly state that 'Persons with diabetes, heart or kidney disease or persons receiving medical treatment should consult a physician before using sodium-free salt' many customers may be unaware 
of its potential severe dangers. The hypertension and vascular disease seen in such common medical conditions as renal failure and diabetes mellitus are typically not safely amenable to increased consumption of potassium due to impaired excretion. The risk of hyperkalemia is further increased by common medications either prescribed for these patient populations (e.g. renin-angiotensin-aldosterone system or beta blockers) or taken over the counter (e.g. non-steroidal anti-inflammatory drugs) [15].

\section{Conclusion}

This patient and the few cases previously described illustrate the importance of educating high-risk patients to avoid excess use of salt substitutes and the need for adequate consumer warnings. Clinicians should be vigilant in monitoring potassium intake from over-the-counter supplements and, in patients presenting with hyperkalemia, a dietary history is important to exclude the use of salt substitutes.

\section{Conflict of interest statement. None declared.}

\section{References}

1. Great Britain. Scientific advisory committee on nutrition. Salt and Health. London: TSO, 2003.

2. He FJ, MacGregor GA. Fortnightly review: beneficial effects of potassium. BMJ 2001; 323: 497-501.

3. Grande Villoria J, Macias Nunez JF, Miralles JM et al. Hyporeninemic hypoaldosteronism in diabetic patients with chronic renal failure. Am J Nephrol 1988; 8: 127-137.
4. Wang WH, Giebisch G. Regulation of potassium (K) handling in the renal collecting duct. Pflugers Arch 2009; 458: 157-168.

5. Lundborg $P$. The effect of adrenergic blockade on potassium concentrations in different conditions. Acta Med Scand Suppl 1983; 672: 121-126.

6. Rosa RM, Silva P, Young JB et al. Adrenergic modulation of extrarenal potassium disposal. N Engl J Med 1980; 302: 431-434.

7. Lee Hamm L, Hering-Smith KS, Nakhoul NL. Acid-base and potassium homeostasis. Semin Nephrol 2013; 33: 257-264.

8. Vraets A, Lin Y, Callum JL. Transfusion-associated hyperkalemia. Transfus Med Rev 2011; 25: 184-196.

9. Thapa S, Brull SJ. Succinylcholine-induced hyperkalemia in patients with renal failure: an old question revisited. Anesth Analg 2000; 91: 237-241.

10. Mali AR, Patil VP, Pramesh CS et al. Hyperkalemia during surgery: is it an early warning of propofol infusion syndrome? J Anesth 2009; 23: 421-423.

11. Lagandré S, Arnalsteen L, Vallet B et al. Predictive factors for rhabdomyolysis after bariatric surgery. Obes Surg 2006; 16: 1365-1370.

12. John SK, Rangan Y, Block CA et al. Life-threatening hyperkalemia from nutritional supplements: uncommon or undiagnosed? Am J Emerg Med 2011; 29: 1237.e1-2.

13. Ray K, Dorman S, Watson R. Severe hyperkalaemia due to the concomitant use of salt substitutes and ACE inhibitors in hypertension: a potentially life threatening interaction. J Hum Hypertens 1999; 13: 717-720.

14. Tobin ML. Persistent severe hyperkalemia in a patient with normal renal function. Med Forum 2012; http://jdc.jefferson. edu/tmf/vol13/iss1/20.

15. Perazella MA. Drug-induced hyperkalemia: old culprits and new offenders. Am J Med 2000; 109: 307-314.

Received for publication: 13.11.13; Accepted in revised form: 25.11 .13 